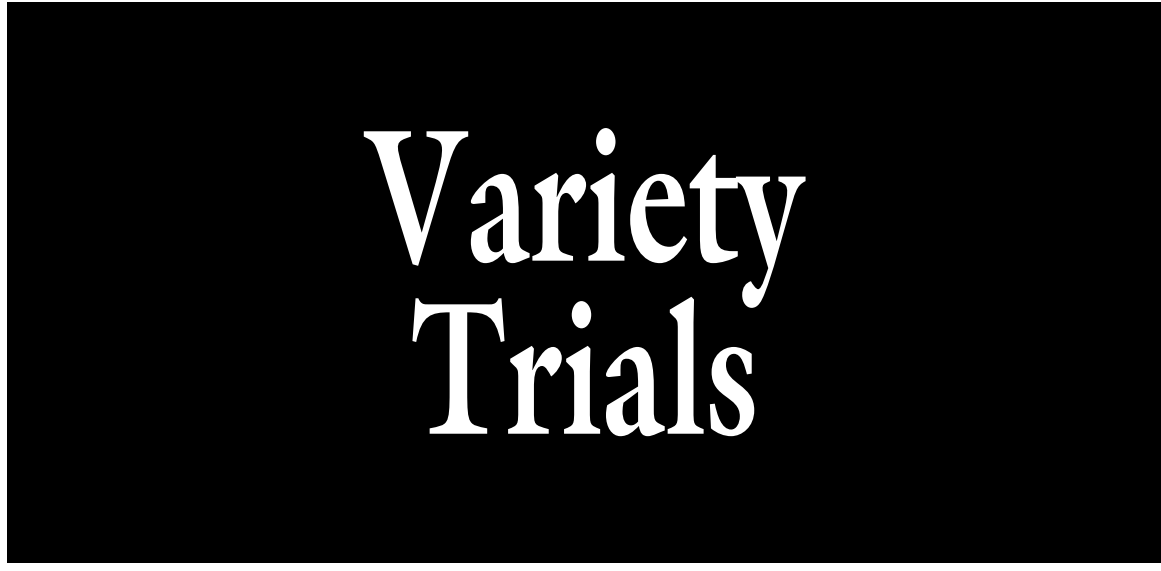

\title{
An Interactive Online Database for Potato Varieties Evaluated in the Eastern United States
}

\author{
Mark E. Clough ${ }^{1}$, George C. Yencho ${ }^{2,12}$, Barbara Christ ${ }^{3}$, \\ Walter DeJong ${ }^{4}$, Donald Halseth ${ }^{5}$, Kathleen Haynes ${ }^{6}$, \\ Melvin Henninger ${ }^{7}$, Chad Hutchinson ${ }^{8}$, Matt Kleinhenz ${ }^{9}$, \\ Greg A. Porter ${ }^{10}$, and Richard E. Veilleux ${ }^{11}$
}

AdDitional INDEX wORDs. Solanum tuberosum, variety development, education, outreach, MySQL, NE1031, relational

SumMARY. Databases are commonly used to coordinate and summarize research from multiple projects. The potato (Solanum tuberosum) research community has invested significant resources in collecting data from multiple states and provinces, and we have developed a web-based database format for the use of researchers, farmers, and consumers. The northeast regional potato variety development project (NE1031) is a U.S. Department of Agriculture, Cooperative State Research, Education, and Extension Service (USDA-CSREES) regional project focused on developing and evaluating the suitability of new varieties and advanced clones from multiple breeding programs for a range of environments. This multistate project and its predecessors have been in existence for more than two decades, and they have resulted in the collection of a significant amount of standardized potato trial data. We have developed an interactive potato variety database that allows researchers and end-users to access and obtain potato variety trial results in one centralized site. The database is populated with the results of potato variety trials conducted in eight states (Florida, Maine, New Jersey, New York, North Carolina, Ohio, Pennsylvania, and Virginia) and two Canadian provinces (Prince Edward Island and Quebec). It currently contains over 35 data features and was developed primarily for scientists interested in potato variety development, growers, and allied industry members. Hypertext mark-up language (HTML) and hypertext preprocessor (PHP) were used to develop the database interface.

$\mathrm{T}$ The USDA-CSREES NE1031 project entitled "Development of New Potato Clones for Improved Pest Resistance, Marketability, and Sustainability in the East" is a project that addresses the needs of the potato industry of the eastern United States through a coordinated process of potato breeding, selection, evaluation, and variety development. Potato breeding and germplasm improvement in this project are conducted by four potato breeding programs (University of Maine, Cornell University, North Carolina State University, and USDA-Agricultural Research Service-Beltsville, MD). Early generation multisite selection, subsequent advanced clone evaluations, and variety trialing are then coordinated across eight eastern states, with collaborative research efforts extending to trial cooperators across the United States and into eastern
Canada. The overall goal of the project is to develop an array of attractive, nutritious, high-yielding, disease- and insect-resistant potato varieties that can be employed by small and large potato producers to enhance marketing opportunities, farm sustainability, and grower profits.

Breeding, selection, and development of adapted, chipping, French fry, specialty-type, and fresh market varieties are emphasized in this project. Selection procedures for processing lines emphasize high dry matter, acceptable fry color, and freedom from internal defects. Fresh market selection and evaluation emphasize excellent appearance, sensory, and nutritional qualities. Development of varieties with durable, multiple resistances to important pathogens and pests, such as late blight (Phytophthora infestans), verticillium wilt (Verticillium dahliae), early blight (Alternaria solani), common scab (Streptomyces spp.), Fusarium dry rot (Fusarium spp.), golden nematode (Heterodera rostochiensis), and colorado potato beetle (Leptinotarsa decemlineata) resistance are long-term priorities.

The NE1031 project is highly collaborative and takes advantage of the multiple potato breeding and variety development programs located in the eastern United States. The project has established a mechanism for sharing and exchanging germplasm and research results between eight participating states and two Canadian provinces. To facilitate easy access of key information, we have developed a web-based, userfriendly potato variety database to facilitate data management and access for the NE1031 project and the entire potato research community. This variety database site was designed primarily with the interests and needs of the potato research community in mind, but it can be accessed easily by farmers, seed brokers, and home gardeners interested in obtaining timely information on regional potato performance. The primary goal when constructing the database was to condense and distill the many variety trials that the NE1031 project conducts into a format that was standardized for key data, such as total and marketable yield, tuber appearance, plant maturity, and specific gravity. However, it was also designed to store unique data collected by 
specialized members of the group, such as disease and insect resistance and cooking qualities. Currently, the database comprises 35 data fields reporting the performance of $<144$ different advanced clones and varieties in multiple trials. Several other potato databases exist worldwide (Table 1). None in North America currently house as much information on released and advanced clones in a single website where the end user has control of the data points in the output as does the NE1031 Potato Database. The database server is located at the North Carolina State University (NCSU), Vernon G. James Research and Extension Center (VGJREC) in Plymouth, NC, and can be accessed at the Eastern Potato Variety Development Database page (Clough, 2009) or by doing a web search on NE1031 potato variety database. The objective of this article is to inform readers of the existence and utility of this resource, and to

The development of this website and the generation of the multi-site potato variety performance data in the database would not have been possible without the support of the following funding sources: USDA CSREES NE1031 Regional Project, USDA CSREES Special Grants for Potato Research, and potato grower groups in the various participating states.

${ }^{1}$ North Carolina State University, Department of Horticultural Science, Vernon G. James Research and Extension Center, 207 Research Station Road, Plymouth, NC 27962

${ }^{2}$ North Carolina State University Department of Horticultural Science, 214-A Kilgore Hall, Box 7609, Raleigh, NC 27695

${ }^{3}$ Pennsylvania State University, Department of Plant Pathology, 212-B Buckhout Laboratory University Park, PA 16802

${ }^{4}$ Cornell University, Department of Plant Breeding and Genetics, 309 Bradfield Hall, Ithaca, NY 14853

${ }^{5}$ Cornell University, Department of Horticulture, 15 D, Plant Science Building, Ithaca, NY 14853

${ }^{6}$ U.S. Department of Agriculture-Agriculture Research Service Plant Sciences Institute, Genetic Improvement of Fruits and Vegetables Laboratory, Building 010A, 10300 Baltimore Avenue, Beltsville, MD 20705

${ }^{7}$ Rutgers University, Department of Plant Biology/ Pathology, 59 Dudley Road, New Brunswick, NJ 08901

${ }^{8}$ University of Florida, Department of Horticultural Sciences, PO Box 110690, Gainesville, FL 32611

${ }^{9}$ Ohio State University, Department of Horticulture and Crop Science, 217 Williams Hall, 1680 Madison Avenue, Wooster, OH 44691

${ }^{10}$ University of Maine, Department of Plant, Soil and Environmental Sciences, Room 114, 5722 Deering Hall, Orono, ME 04469

${ }^{11}$ Virginia Polytechnic Institute and State University, Department of Horticulture, 206 Saunders Hall, Blacksburg, VA 24061

${ }^{12}$ Corresponding author. E-mail: craig_yencho@ncsu. edu.

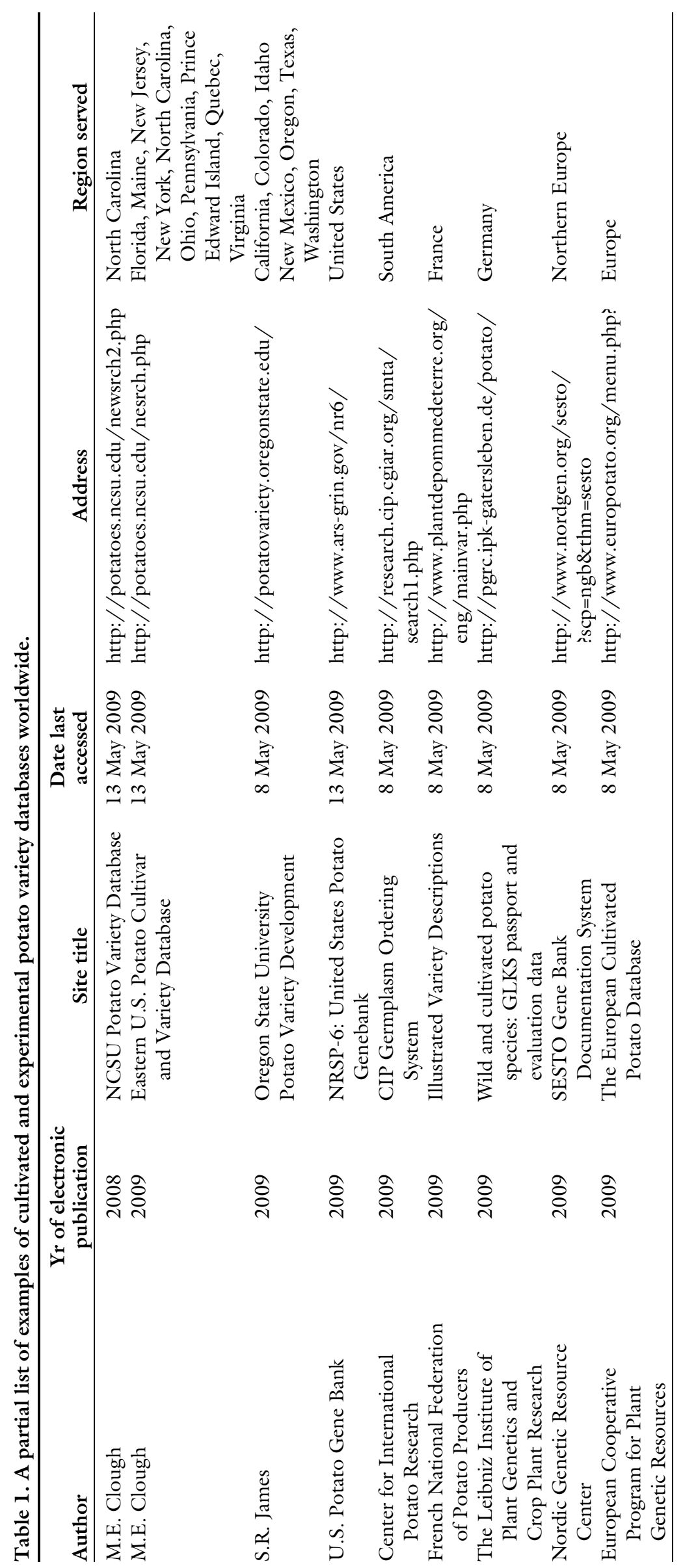




\begin{tabular}{|c|c|c|c|c|c|c|c|c|c|c|c|c|c|c|}
\hline Clone & STATEORPROVINCE & County & TRIALdesignation & Year & TOTAL YIELD & MARKETABLE YIELD & $\%$ STANDARD & STANDARD VARIETY & REPUCATIONS & \%SSIZE 1 & \%SIZE 2 & \%SIZE 3 & \%SIZE 4 & \%SIZE 5 \\
\hline A0008-1TE & NYUpsate & TOMPKINS & RUS & 2007 & 134 & 61 & 34 & RUSSET BURBANK & 4 & 34 & 47 & 13 & 6 & 0 \\
\hline A00293-2Y & NC & Washington & SPVT & 2008 & 206 & 101 & 93 & Chieftain & 4 & 8 & 28 & 22 & 0 & 0 \\
\hline A81386-1 & ME & Aroostook & AFRUS & 1998 & 327 & 303 & 67 & Russet Burbank & 4 & 21 & 38 & 26 & 8 & 7 \\
\hline A81386-1 & ME & Aroostook & SJVRU & 1998 & 399 & 219 & 98 & Russet Burbank & 4 & 13 & 35 & 32 & 14 & 7 \\
\hline A81386-1 & ME & Aroostook & AFRUS & 1999 & 335 & 297 & 118 & Russet Burbank & 4 & 16 & 40 & 27 & 13 & 4 \\
\hline A81386-1 & ME & Aroostook & SJVRU & 1999 & 351 & 317 & 114 & Russet Burbank & 4 & 9 & 31 & 29 & 15 & 15 \\
\hline A81386-1 & NC & Washington & RUS & 1998 & 281 & 267 & 89 & CenturyRusset & 4 & 2 & 17 & 79 & 0 & 0 \\
\hline A81386-1 & NC & Washington & RUS & 1999 & 169 & 159 & 139 & RussetNorkotah3117 & 4 & 4 & 15 & 79 & 0 & 0 \\
\hline A81386-1 & NJ & Cumberland & $E 9903$ & 1999 & 212 & 176 & 48 & Sup & 1 & 13 & 60 & 23 & 0 & 0 \\
\hline A81386-1 & NJ & Hunterdon & E9908 & 1999 & 472 & 374 & 84 & Sup & 4 & 11 & 39 & 26 & 13 & 12 \\
\hline A81386-1 & NY Upstate & Tompkins & Rus/Longwhite & 1998 & 368 & 205 & 110 & RussetBurbank & 4 & 20 & 57 & 14 & 5 & 3 \\
\hline A81386-1 & NY Upstate & Tompkins & Rus/Longwhite & 1999 & 457 & 282 & 121 & RussetBurbank & 4 & 15 & 38 & 24 & 12 & 11 \\
\hline A81386-1 & PA & Centre & NE184 & 1998 & 312 & 226 & 75 & Kennebec & 4 & 24 & 62 & 11 & 0 & 0 \\
\hline A84180-8 & $\mathrm{FL}$ & St.Johns & NE & 1998 & 298 & 191 & 50 & Atlantic & 4 & 25 & 63 & 1 & 0 & 0 \\
\hline A84180-8 & $\mathrm{FL}$ & St.Johns & NE & 2000 & 355 & 327 & & & 4 & 5 & 45 & 36 & 11 & 0 \\
\hline A84180.8 & ME & Aroostook & AFRUS & 1998 & 366 & 360 & 79 & Russet Burbank & 4 & 18 & 49 & 25 & 7 & 1 \\
\hline A84180-8 & ME & Aroostook & SJVRU & 1998 & 383 & 327 & 147 & Russet Burbank & 4 & 13 & 56 & 26 & 4 & 1 \\
\hline A84180-8 & $\mathrm{ME}$ & Aroostook & AFRUS & 1999 & 337 & 300 & 120 & Russet Burbank & 4 & 12 & 50 & 30 & 8 & 1 \\
\hline A84180-8 & ME & Aroostook & SJVRU & 1999 & 348 & 281 & 101 & Russet Burbank & 4 & 8 & 30 & 40 & 15 & 7 \\
\hline A84180-8 & ME & Aroostook & AFRUS & 2000 & 288 & 224 & 70 & Russet Burbank & 4 & 19 & 51 & 24 & 5 & 1 \\
\hline A84180-8 & NC & Washington & RUS & 1998 & 221 & 154 & 51 & CenturyRusset & 4 & 5 & 29 & 42 & 0 & 0 \\
\hline A84180-8 & NJ & Cumberland & E9801 & 1998 & 348 & 257 & 86 & Sup & 1 & 10 & 49 & 25 & 0 & 0 \\
\hline A84180.8 & NJ & Cumberland & E9806 & 1998 & 516 & 390 & 148 & Sup & 4 & 15 & 26 & 30 & 20 & 8 \\
\hline A84180.8 & NJ & Cumberland & E9903 & 1999 & 323 & 243 & 66 & Sup & 1 & 7 & 43 & 27 & 5 & 0 \\
\hline A84 $180 \cdot 8$ & NJ & Hunterdon & E9908 & 1999 & 497 & 306 & 69 & Sup & 4 & 18 & 35 & 26 & 14 & 7 \\
\hline A84180.8 & NY Upstate & Tompkins & Rus/Longwhite & 1998 & 274 & 166 & 89 & RussetBurbank & 4 & 28 & 54 & 15 & 2 & $i$ \\
\hline A84180.8 & PA & $\begin{array}{l}\text { Cempkins } \\
\text { Centre }\end{array}$ & NE184 & 1998 & 269 & 183 & 61 & Kennebec & 4 & 26 & 56 & 11 & 0 & 0 \\
\hline A86102.6 & $\mathrm{FL}$ & St.Johns & NE & 1998 & 373 & 257 & 68 & Atlantic & 4 & 12 & 65 & 4 & 0 & 0 \\
\hline A86102.6 & ME & Aroostook & AFRUS & 1998 & 349 & 322 & 71 & Russet Burbank & 4 & 25 & 48 & 15 & 9 & 3 \\
\hline A86102.6 & $\mathrm{ME}$ & Aroostook & SJVRU & 1998 & 441 & 348 & 156 & Russet Burbank & 4 & 16 & 47 & 28 & 7 & 2 \\
\hline A86102.6 & $M E$ & Aroostook & AFRUS & 1999 & 369 & 319 & 127 & Russct Burbank & 4 & 10 & 38 & 31 & 16 & 5 \\
\hline A86102.6 & ME & Aroostook & SJVRU & 1999 & 422 & 311 & 112 & Russet Burbank & 4 & 6 & 26 & 33 & 21 & 14 \\
\hline A86102.6 & NJ & Cumberland & E9801 & 1998 & $\begin{array}{l}462 \\
359\end{array}$ & 270 & 90 & Sup & $i$ & 10 & $\begin{array}{l}20 \\
49\end{array}$ & 24 & 3 & 0 \\
\hline A86102.6 & NJ & Cumberland & E9806 & 1998 & 436 & 297 & 112 & Sup & 4 & 25 & 42 & 22 & 8 & 3 \\
\hline A86102.6 & NY Upstate & Tompkins & Rus/Longwhite & 1998 & 379 & 188 & 101 & RussetBurbank & 4 & 34 & 54 & 12 & 1 & 0 \\
\hline A96510.4Y & NY Upsa:e & TOMPKINS & RUS & 2007 & 411 & 279 & 153 & RUSSET BURBANK & 4 & 8 & 25 & 42 & 13 & 12 \\
\hline$A 96510.4 Y$ & NYUpsa:e & TOMPKINS & RUS & 2008 & 332 & 216 & 119 & RUSSET BURBANK & 4 & 11 & 30 & 38 & 13 & 7 \\
\hline A $97066 \cdot 42 \mathrm{LB}$ & NYUpsta:e & TOMPKINS & RUS & 2008 & 330 & 125 & 69 & RUSSET BURBANK & 4 & 8 & 20 & 26 & 29 & 16 \\
\hline $\mathrm{AC} 96052.1 \mathrm{RU}$ & NY Upstate & TOMPKINS & RUS & 2008 & 257 & 187 & 103 & RUSSET BURBANK & 4 & 22 & 37 & 16 & 4 & 1 \\
\hline $\mathrm{AC} 97097 \cdot 14 \mathrm{~W}$ & NY Upsta:e & TOMPKINS & CO-TX.ND & 2007 & 21 & 284 & 110 & ATLANTIC & 4 & 4 & 40 & 46 & 7 & 4 \\
\hline $\mathrm{AC} 97521-\mathrm{RY}$ & NY Upsta:e & TOMPKINS & RED & 2008 & 362 & 297 & 119 & & 2 & 10 & 66 & 22 & 2 & 0 \\
\hline $\mathrm{AC} 97521-\mathrm{RY}$ & NY Upsta:e & WAYNE & GROWER & 2008 & 471 & 320 & 78 & CHEFTAN & $i$ & 22 & 78 & & 0 & 0 \\
\hline Accent & ME & Aroostook & AFEME & 1998 & 486 & 434 & 109 & Superior & 4 & 5 & 54 & 39 & 1 & 0 \\
\hline ACRedisland & $\mathrm{FL}$ & St.Johns & NE1014 & 2003 & 473 & 410 & 86 & Atlantic & 4 & 6 & 51 & 29 & 8 & 0 \\
\hline ACRedisland & $\mathrm{FL}$ & St. John's & NE 1014 & 2004 & 363 & 286 & 68 & Atlantic & 4 & 10 & 62 & 16 & 3 & 0 \\
\hline ACRedisland & $\mathrm{FL}$ & St. Johns & NE1014 & 2005 & 256 & 185 & 71 & Atlantic & 4 & 24 & 68 & 6 & 1 & 0 \\
\hline & ME & & AFEME & 200 & 308 & 274 & 100 & Chieftain & 4 & 4 & 61 & 35 & 1 & 0 \\
\hline ACRedisland & ME & Aroostook & SJV & 2003 & 470 & 417 & 114 & Chieftain & 4 & 1 & 29 & 55 & 14 & 1 \\
\hline ACRedlsland & ME & Aroostook & AFEME & 2004 & 355 & 320 & 89 & Chieftain & 4 & 5 & 62 & 31 & 2 & 0 \\
\hline ACRedisland & $M E$ & Aroostook & SJV & 2004 & 387 & 359 & 86 & Chieftain & 4 & 3 & 51 & 43 & 3 & 0 \\
\hline
\end{tabular}

Fig. 1. A partial view of potato variety data submitted in Excel (Microsoft, Redmond, WA) format for the Northeast Potato Variety Development NE1031 project database. The top row is the name for each field. In the columns below each name are the data collaborators have sent for input into the database. The columns for clone, state or province, county, trial designation, and year are used as identifiers, which enables sorting and retrieval by variety. Columns to the right of the year column contain data specific to each variety in a given trial, location, and year.

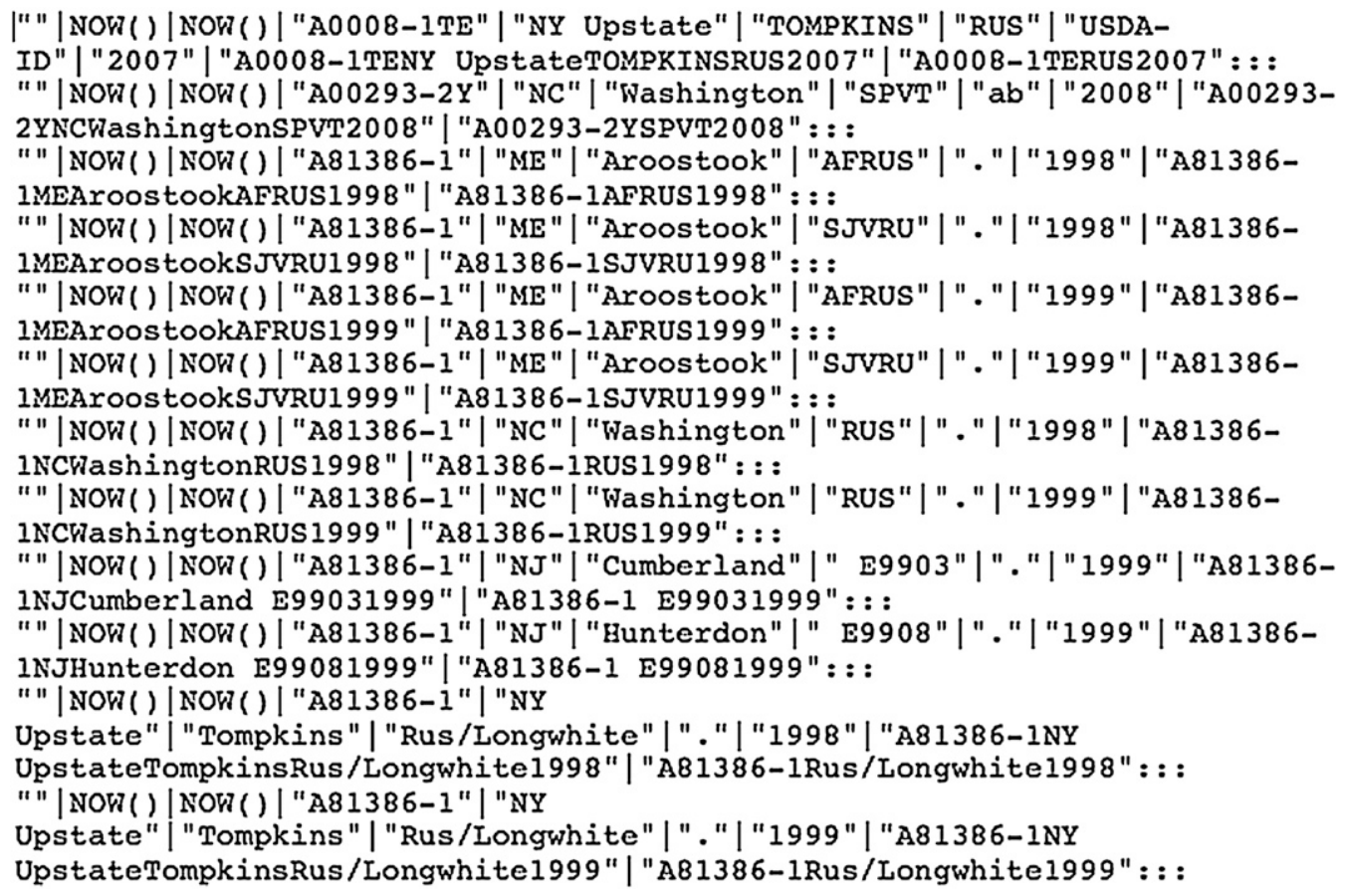

Fig. 2. A portion of a text file created from the data submitted by collaborators. This file contains variety names and information relating to where and when the varieties were grown. 
demonstrate how easily such a resource can be developed.

\section{Materials and methods}

Database Design. The database runs on a Mac OS X Server (version 10.4.10; Apple Computers, Cupertino, CA) with a dual $2.7 \mathrm{GHz}$ PowerPC G5 processor. This is a stand-alone server located at NCSU, VGJREC. The data are submitted by collaborators in Excel (Microsoft, Redmond, WA) spreadsheet format (Fig. 1) and converted into two text files where various characters are used to delimit clones and clone elements (Figs. 2 and 3). The clone elements consist of descriptors such as year, trial, and trial location, and data specific to the performance of a clone. Using the Terminal software package provided on the Mac OS X Server, the elements of the two text files are imported into tables in a format recognized by MySQL $\AA$ (MySQL ${ }^{\circledR}$, Cupertino, CA), which is an open source relational database management system based on structured query language (SQL) (TechTerms.com, 2007). A relational database is a collection of tables that refer to each other through a common set of parameters identified in each table (Meloni, 2002). In the eastern potato variety development database, we chose to have three sets of common data elements consisting of a combination of five specific elements. These elements consist of the variety name (or clone number), the state (or province), the county, the trial designation, and the year. For example, the first identifier contains all five data points, the second consists of the variety, trial designation, and year, and the final has only the variety and year. The purpose of having multiple identifiers is to allow data retrieval at varying levels of specificity. Data points related to specific locations not collected by each cooperator are handled easily by the MySQL ${ }^{\circledR}$ engine provided if the missing data are coded as missing and not zeros. When calculating an average, it will ignore all data that has a "." in place of the data point. All data are encapsulated in quotation marks (“"), fields are delimited by the vertical bar character $(\mid)$, and the end of an entry is denoted by three colons (:::). The preceding delimiters used for coding are arbitrarily designated by the administrator and are dictated to the processor to define the data points. Each of the files is also coded with the statement: NOW(), two times at the head of the entry. The NOW() statement is an SQL derived command that dates each entry. The first statement stamps the date of upload to the database, the other records the last date the entry was altered.

INTERNET INTERFACE DESIGN. The original interface for the NE1031 eastern potato variety development database was patterned after a database developed by S.R. James (Oregon State University) that used HTML coding. This site is no longer operational. To make a more user-friendly interface, we migrated to a combination of PHP and HTML web programming, which allows users to more narrowly define the available list of varieties and advanced lines. The web interface allows visitors to limit performance of searches by variety release status, tuber color, and or plant maturity. Any combination of these three traits can be used to limit the output of lines displayed for each search. Our latest design changes have also incorporated a standardized layout using Dreamweaver (version 8.0; Macromedia, San Francisco, CA), giving the website a more professional appearance.

After a user decides which type of clones he/she is interested in (e.g., by tuber color: red, white, purple, and/or by maturity: early, midseason, late), the list is reduced to a specific set of clones, and the output can then be

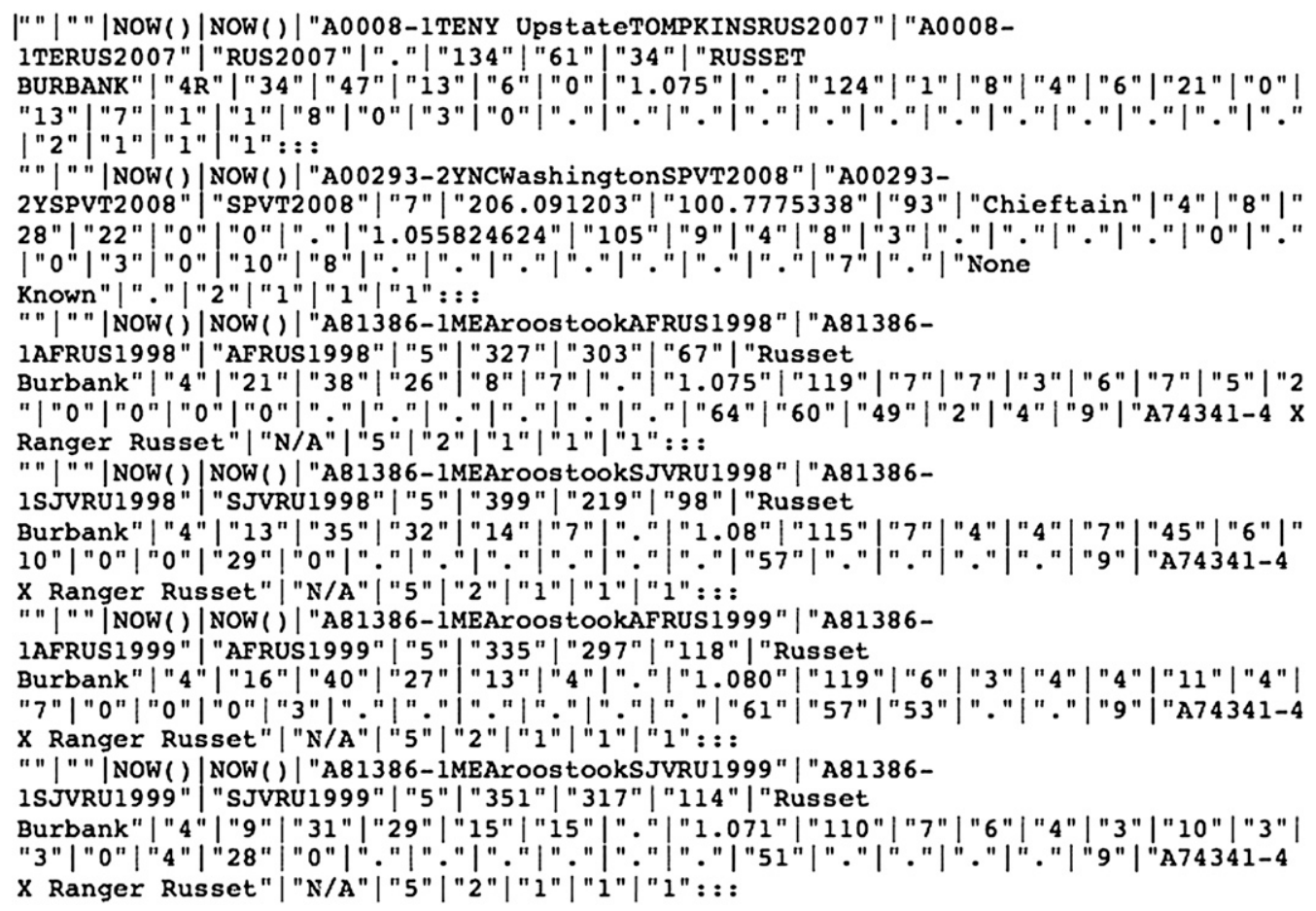

Fig. 3. A portion of a text file created from the data submitted by collaborators. This file contains all of the trial data. 


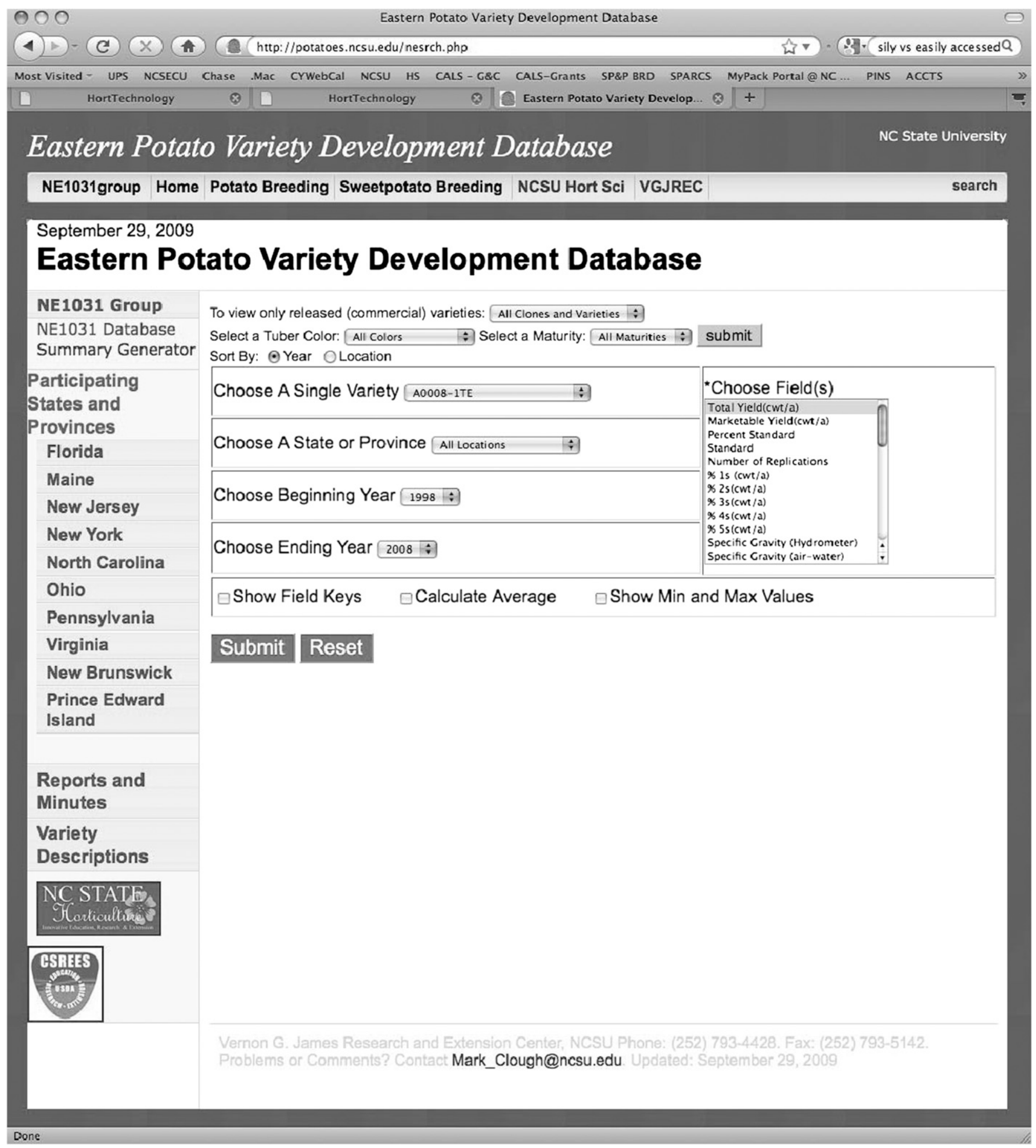

Fig. 4. The home page of the NE1031 eastern potato variety development database as shown on a Mac OS X Server (version 10.4.10; Apple Computers, Cupertino, CA) using the Safari browser (version 3.2.1; Apple Computers). 
further constrained by selecting locations, traits, and years of interest (Fig. 4). Before clicking the submit button, the user can also choose how the data are sorted and the formatting of the summaries printed. The output is presented in a tabular form and is expressed using PHP and HTML (Fig. 5).

A second interface was constructed to allow users to build a one-page summary (Fig. 6) to compare a variety of interest with a standard variety that can also be selected by the user. The summary includes yield, color, maturity, chipping scores, intended use, and known disease, insect, and virus resistances. If available, an image of the variety is shown on the summary.

\section{Results and discussion}

To date, individuals from 26 countries, five continents, 26
American states, and five Canadian provinces have used the database. The average length of visit is between $\mathrm{l}$ and $2 \mathrm{~min}$, and the longest hit lasted 62 min (ActiveMeter, Calgary, AB, Canada). The database users have been diverse, ranging from government agencies and universities to growers and individuals from urban areas.

Future improvements for the database include building another

NE1031 Potato Variety Dat.

\section{PeterWilcox(B1816-5)}

\begin{tabular}{|c|c|c|c|c|c|c|c|c|c|c|c|c|}
\hline Clone & \begin{tabular}{|l|} 
State or \\
Province
\end{tabular} & County & Year & \begin{tabular}{|c|} 
Marketable \\
cwta
\end{tabular} & $\% 1$ 's & $\% 2$ 's & \%3's & $\begin{array}{c}\text { Specific Gravity } \\
\text { (Air/Water) }\end{array}$ & \begin{tabular}{|l|} 
Days to \\
Harvest
\end{tabular} & Maturity & Shape & $\begin{array}{c}\text { Overall } \\
\text { Appearance }\end{array}$ \\
\hline PeterWilcox(B1816-5) & $\mathrm{NC}$ & Washington & 2005 & 151.1 & 12 & 62 & 20 & 1.06694560 & 112 & 5 & 5 & 6 \\
\hline PeterWilcox(B1816-5) & NC & Washington & 2006 & 326.1 & 3 & 30 & 57 & 1.06555837 & 113 & 5 & 5 & 6 \\
\hline PeterWilcox(B1816-5) & $\mathrm{NC}$ & \begin{tabular}{|l|} 
Beaufort \\
\end{tabular} & 2007 & 84.44 & 5 & 0 & 83 & 1.06759631 & 105 & 8 & 5 & 6 \\
\hline PeterWilcox(B1816-5) & NC & Mitchell & 2007 & 129.1 & 20 & 0 & 72 & 1.06718061 & 171 & 3.75 & 5 & 6 \\
\hline PeterWilcox(B1816-5) & $\mathrm{NC}$ & Washington & 2007 & 62.16 & 10 & 49 & 36 & 1.07379483 & 101 & 4 & 5 & 5 \\
\hline PeterWilcox(B1816-5) & NC & Washington & 2007 & 156.6 & 7 & 36 & 52 & 1.07608100 & 101 & 4 & 5 & 6 \\
\hline PeterWilcox(B1816-5) & $\mathrm{NC}$ & Pamlico & 2007 & 145.5 & 7 & 0 & 87 & 1.06875784 & 101 & 4 & 5 & 5 \\
\hline PeterWilcox(B1816-5) & NC & Pasquotank & 2007 & 163.6 & 23 & 0 & 73 & 1.07019591 & 105 & 3.5 & 5 & 7 \\
\hline PeterWilcox(B1816-5) & $\mathrm{NC}$ & Pasquotank & 2008 & 70.45 & 38 & 0 & 60 & 1.07194899 & 104 & 6.5 & 4 & 6 \\
\hline PeterWilcox(B1816-5) & NC & Pamlico & 2008 & 144.9 & 15 & 0 & 83 & 1.07255936 & 103 & 4 & 3 & 5 \\
\hline PeterWilcox(B1816-5) & $\mathrm{NC}$ & Washington & 2008 & 107.0 & 8 & 58 & 25 & 1.06430635 & 105 & 4.5 & 4 & 4 \\
\hline PeterWilcox(B1816-5) & $\mathrm{NC}$ & Washington & 2008 & 116.4 & 7 & 40 & 33 & 1.05917667 & 105 & 5 & 4 & 4 \\
\hline PeterWilcox(B1816-5) & $\mathrm{NC}$ & Mitchell & 2008 & 30.52 & 42 & 0 & 38 & 1.07659151 & 126 & 3.25 & 5 & 6 \\
\hline PeterWilcox(B1816-5) & $\mathrm{NC}$ & Beaufort & 2008 & 63.61 & 13 & 0 & 80 & 1.07682659 & 98 & 5 & 5 & 6 \\
\hline \multicolumn{4}{|c|}{ Averages } & 125 & 15 & 20 & 57 & 1.070 & 111 & 5 & 5 & 6 \\
\hline \multicolumn{4}{|r|}{ Min } & 30.52 & 3 & 0 & 20 & 1.05917667 & 98 & 3.25 & 3 & 4 \\
\hline \multicolumn{4}{|r|}{$\operatorname{Max}$} & 326.1 & 42 & 62 & 87 & 1.07682659 & 171 & 8 & 5 & 7 \\
\hline
\end{tabular}

Back To Search Page

This Page Was Created By: Mark E. Clough, Researcher

On 9/26/02 And Last Modified On 4/10/09

Fig. 5. An example of the database output for the variety Peter Wilcox in North Carolina showing county, year, marketable yield, percentage of size, specific gravity, plant maturity, tuber shape, and overall. User's can choose to have the keys to the data fields displayed when the output is generated if needed. 


$(\mathrm{C}+\mathrm{C}$ http://potatoes.ncsu.edu/nesum.php Potato Summary Sheet
Potato Summary Sheet

\section{PeterWilcox(B1816-5)}

Parentage:

B0810-1 X B0918-5

Skin Color: Purple

Flesh Color: Yellow

Maturity: Mid to Late Maturing

Total Yield: $283 \mathrm{cw} / \mathrm{A}$

Marketable Yield: $231 \mathrm{cw} / \mathrm{A}$

Percent DarkRedNorland: $98 \%$ (non parallel)

$97 \%$ (parallel)
No Picture Available

Average Incidence of Heat Necrosis: $1 \%$

Rating of tubers expressing symptoms: Very Slight

Average Incidence of Other Tuber Defects:

Hollow Heart: $1 \%$

Vascular Discoloration: $3 \%$

Scab: $3 \%$

Soft Rot: $1 \%$

Growth Cracks: $2 \%$

Misshapes: $3 \%$

Greens: $2 \%$

\author{
Disease Resistance: \\ N/A \\ Number of Trials: 50 \\ Trial Locations: \\ FL ME NC NJ NY Long Island NY Upstate OH PA PEI QC \\ VA
}

Years Evaluated: 2005 to 2008

Chip Rating: Not Acceptable (Visual field score)

Not Acceptable (Agtron field score)

Good, Light or Golden (Agtron $45^{\circ}$ score)

No Chip Rating (Agtron $40^{\circ}$ score)

Back To Search Page

This Page Was Created By: Mark E. Clough, NCSU-Researcher and Extension Associate for the NE1031 Northeast Regional Participatory Group The information provided above is a variety performance summary from data supplied to the NE1031 Potato Database by our participating members and reflects performance in those States and Provinces.

Last Modified On January 3,2008

Fig. 6. An example of a one-page data summary for the variety Peter Wilcox generated within the NE1031 eastern potato variety development database site.

interface that will allow the comparison of multiple varieties for a set of user-defined parameters. New features will be added to the existing interfaces to allow a user to search for varieties with resistance to specific virus, bacterial, fungal, and/or insect pests. This will increase the overall usefulness of the database.

The utility of the NE1031 eastern potato variety development database has lead to some discussion regarding the development of a national or
North American potato variety trial database. This is a good goal; however, a major impediment to implementing such a resource relates to the diverse set of evaluation criteria collected by the individual potato research groups and regions across the country. One of the key factors enabling the development of the NE1031 potato variety database was that all regional potato cooperators agreed to evaluate our materials using a standardized set of evaluation descriptors.

\section{Literature cited}

Clough, M.E. 2009. Eastern potato variety development database. 29 Sept. 2009. $<$ http://potatoes.ncsu.edu/nesrch. php>.

Meloni, J.C. 2002. Sams teach yourself MySQL in 24 hours. Sams Publishing, Indianapolis.

TechTerms.com. 2007. MySQL. 29 Sept. 2009. <http://www.techterms.com/ definition/mysql>. 